\title{
Technical Note: Comparing and ranking soil drought indices performance over Europe, through remote-sensing of vegetation
}

\author{
E. Peled ${ }^{1}$, E. Dutra ${ }^{2}$, P. Viterbo ${ }^{2,3}$, and A. Angert ${ }^{1}$ \\ ${ }^{1}$ The Institute of Earth Sciences, The Hebrew University of Jerusalem, Jerusalem 91904, Israel \\ ${ }^{2}$ IDL, CGUL, University of Lisbon, Lisbon, Portugal \\ ${ }^{3}$ Institute of Meteorology, Lisbon, Portugal
}

Received: 24 August 2009 - Published in Hydrol. Earth Syst. Sci. Discuss.: 5 October 2009

Revised: 27 January 2010 - Accepted: 8 February 2010 - Published: 12 February 2010

\begin{abstract}
In the past years there have been many attempts to produce and improve global soil-moisture datasets and drought indices. However, comparing and validating these various datasets is not straightforward. Here, interannual variations in drought indices are compared to interannual changes in vegetation, as captured by NDVI. By comparing the correlations of the different indices with NDVI we evaluated which drought index describes most realistically the actual changes in vegetation. Strong correlation between NDVI and the drought indices were found in areas that are classified as warm temperate climate with hot or warm dry summers. In these areas we ranked the PDSI, PSDI-SC, SPI3, and NSM indices, based on the interannual correlation with NDVI, and found that NSM outperformed the rest. Using this best performing index, and the ICA (Independent Component Analysis) technique, we analyzed the response of vegetation to temperature and soil-moisture stresses over Europe.
\end{abstract}

\section{Introduction}

Having reliable information on the spatial and temporal variability of soil-moisture is a key to many practical and scientific problems. Reliable soil-moisture data crucially improve long-term weather forecasts (Seneviratne et al., 2006; Ferranti and Viterbo, 2006), and help to prepare better for drought. In addition, long-term changes in soil-moisture and especially droughts, induced by climate-change (Sheffield and Wood, 2007), can have important effects on the ter-

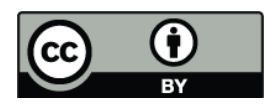

Correspondence to: A. Angert

(angert@huji.ac.il) restrial biosphere, which feedback into the climate system through the carbon cycle (Angert et al., 2005; Fung et al., 2005).

Given these needs, there have been many attempts to produce and improve global soil-moisture and drought indices datasets (Dai et al., 2004; Dutra et al., 2008; McKee et al., 1993; Palmer, 1965; Wells et al., 2004). Allegedly, some of these datasets have advantages over others. However, comparing and validating these various datasets is not an easy task.

Ground-based soil-moisture measurements are accurate, but hard to compare to the large scale datasets because of their point-based nature, their limited coverage, and the wellknown high spatial variability of soils. Remote sensing methods on the other hand, provide extensive spatial and temporal coverage of soil-moisture, but these methods can only sense the top few centimeters of soil, and become less sensitive to soil-moisture in vegetated regions as the vegetation water content increases (Wang et al., 2007). Another approach focuses on assessing soil-moisture, not by modeling, but by remote sensing of vegetation.

This approach uses a well-known index for assessing vegetation spatial and temporal variability: the Normalized Difference Vegetation Index (NDVI). This index is based on the differential absorption of red and near infrared (NIR) light by leaves, and is linearly correlated with the fraction of photosynthetic active radiation absorbed by plants (Tucker and Sellers, 1986). The basic idea of this approach is that temporal variations in soil-moisture cause changes in vegetation, which can be captured by NDVI. However, the correlations between soil-moisture estimated by this approach to field measurements are low (Tadesse et al., 2005; Wang et al., 2007), probably because soil-moisture is not the only factor

Published by Copernicus Publications on behalf of the European Geosciences Union. 
controlling vegetation and factors like temperature and management can also come into play. Using NDWI (Normalized Difference Water Index) instead of NDVI did not produce improved correlations (Gu et al., 2008).

Due to the limitations of the various methods for validating soil-moisture indices discussed above, we suggest here a somewhat different approach for using the NDVI signal. In the current study, interannual variations in indices for drought are compared to interannual changes in vegetation, as captured by NDVI. The NDVI signal is affected by changes in vegetation leaf area and chlorophyll content, induced not only by soils-moisture but also by other natural and anthropogenic factors such as temperature, and management. However, in areas and seasons in which soil-moisture is the main limiting factor, a better drought (as an indicator of soil-moisture stress) estimate will result in a better correlation with NDVI. Thus, comparing the correlation of the different indices with NDVI will enable to evaluate which drought index provides the most reliable representation of water stress. This is of course true only if all drought indices are derived independently of NDVI (for example, no optical reflectance data were used to create them). One should emphasize that the correlation for a single pixel may be randomly high. However, by integrating large areas, and by focusing on long time series of interannual variability, we mostly eliminate this problem. We have set our focus on the time of year when drought stress is mostly expected - namely summer (and to a lesser extent, spring). In addition to ranking the drought indices based on correlation with NDVI, we have explored the spatial distribution of this correlation, and its relationship with other variables. In particular we have looked on how the relationship between soil-moisture and NDVI changes with land-cover.

It must be stressed that in our view, NDVI cannot serve as a direct proxy for soil-moisture, both because no NDVI dataset captures perfectly the changes in vegetation, and because of the other, natural and manmade, factors which control vegetation (mentioned above). In a perfect situation, validation and ranking of drought indices would be done versus in-situ measurements. In practice however, the extent of datasets covering in-situ, point based, measurements, is far from providing a complete temporal and spatial coverage, against which large-scale drought products can be tested. Thus, while point based measurement will continue to be the primary source for validation, the NDVI approach we suggest here can be very useful in complementing it.

\section{Data and methods}

\subsection{Drought indices}

In the current research we have used five indices for drought.

\subsubsection{The Palmer Drought Severity Index (PDSI)}

This index is a standardized measure of surface soil-moisture conditions which integrates moisture inputs (precipitation), and outputs (drainage and evapotranspiration) as well as the local Available Water Content (AWC) of the soil. Here, we have used the global PDSI calculated by Dai et al. (2004) at a resolution of $2.5^{\circ}$ by $2.5^{\circ}$, based on observed monthly surface air temperature and precipitation.

Despite its popularity, PDSI has several limitations; these include an inherent time scale, and the uncertainty of the index to the amount of water available for plant use in different soil types. A common critique of the PDSI is that the behavior of the index at various locations is inconsistent, making spatial comparisons of PDSI values difficult (Heim, 2002; Lloyd-Hughes and Saunders, 2002; Sims et al., 2002).

\subsubsection{The Self-Calibrating PDSI (SC-PDSI)}

This index was suggested to be a more appropriate index for geographical comparison of climates of diverse regions (Wells et al., 2004). SC-PDSI improves the performance of the PDSI by automating the calculations of the empirical constants used in the PDSI algorithm. This was achieved by determining, for each location, the climatic characteristic weighting factor $(K)$ using the historical climatic data from only that location. In a similar way, the duration factors are calculated separately for wet and dry spells, thus influencing the sensitivity of the index for changes in the moisture regime (Van Der Schrier et al., 2006). Due to the computed modifications, the SC-PDSI is claimed to behave in a consistent, predictable manner as well as to represent the climates of diverse locations in a more realistic way (Wells et al., 2004). We have used a $0.5^{\circ}$ grid, monthly temporal resolution dataset (Van Der Schrier et al., 2006).

\subsubsection{The Standardized Precipitation Index (SPI)}

The Standardized Precipitation Index, proposed by McKee et al. (1993) is an alternative to PDSI, and was designed to quantify the precipitation deficit for multiple time scales. SPI represents a statistical z-score or the number of standard deviations (following a gamma probability distribution transformed to a normal distribution) for the deviation of precipitation, accumulated over a given period, from the mean. One advantage of SPI is that it can be tailored to specific needs. For example, SPI is routinely calculated for 1, 3, and 6, months (Heim, 2002; McKee et al., 1993), and other time scales, up to 48 months, are also in use. An obvious disadvantage it that SPI accounts only for moisture inputs, but not for outputs (i.e., variability in the rates of evapotranspiration or drainage is not considered). In the current study we have calculated SPI3 (i.e., with 3 months aggregation period), which was previously reported to provide best 
correlations with NDVI (Ji and Peters, 2003). The SPI3 was calculated from two precipitation datasets:

1. The Global Precipitation Climatology Project (GPCP), which merges data from over 6000 rain gauge stations and from satellite observations into a $2.5^{\circ}$ global grid, monthly rainfall dataset (Xie et al., 2003).

2. The European Centre for Medium-Range Weather Forecasts (ECMWF) Re-Analysis project (ERA-40), which produces a long time-series of consistent meteorological analyses based on simulations with the best-fit between modeled results and observations (Uppala et al., 2005). We have used the $1^{\circ}$ spatial resolution and averaged over the daily precipitation accumulation data to monthly temporal resolution.

\subsubsection{The Normalized total depth Soil Moisture (NSM)}

The Normalized total depth Soil Moisture is a model-based drought index proposed recently (Dutra et al., 2008). This index represents the standardize anomalies in soil-moisture. Soil-moisture is calculated by the TESSEL land surface model (Viterbo and Beljaars, 1995; Van den Hurk et al., 2000) forced by the ERA-40 precipitation, downwelling radiation and near surface meteorology. The model uses four soil layers that vary in depth $(0-7,7-28,28-100$ and 100 $289 \mathrm{~cm}$ ). The NSM is based on the integrated soil-moisture over these four layers. So far the NSM dataset is available for Europe. The model output $1^{\circ}$ spatial resolution was averaged into monthly time scale.

\subsection{NDVI data}

In this study, we have used the Global Inventory Modeling and Mapping Studies (GIMMS) version-g NDVI dataset on $1^{\circ}$ by $1^{\circ}$, and $8 \mathrm{~km}$ spatial resolutions and monthly temporal resolution from 1982 to 2002 (Pinzon et al., 2005; Tucker et al., 2005).

\subsection{Land-cover data}

The Vegetation Continuous Fields (VCF) collection contains estimates of the proportional coverage of woody vegetation, herbaceous vegetation, and bare ground in each grid-cell (500 $\mathrm{m}$ resolution). The product is derived from all seven bands of the MODerate-resolution Imaging Spectroradiometer (MODIS) sensor onboard NASA's Terra satellite (Hansen et al., 2003a, b).

\subsection{Statistical analyses}

All drought indices datasets were re-gridded to $1^{\circ}$ by $1^{\circ}$ by linear interpolation (or by averaging), to enable comparison with the NDVI dataset.

For NDVI ( $1^{\circ}$ resolution) and for each drought index, the average summer (June, July, August - JJA) and spring
(March, April, May - MAM) values were calculated for every grid cell in Europe for the period 1982-2002 (45X66 grid cells). The interannual variability was captured by calculating the JJA and MAM normalized anomalies.

The linear correlation coefficient $(r)$ between the time series of NDVI anomalies and the soil-moisture anomalies in each of the indices was calculated for every grid cell in $\mathrm{Eu}-$ rope. In addition, we have calculated the linear correlation coefficient $(r)$ between the time series of area-mean NDVI anomalies and the area-mean soil-moisture anomalies, for specific areas (see results and discussion). We have also applied to the NDVI data set the Independent Component Analysis (ICA), which is an advanced method for separating a multivariate signal into additive subcomponents (Hyvrinen and Oja, 2000). By this analysis we have tried to separate the response of NDVI to temperature and soil-water stress.

One area, Iberia, was chosen for a more detailed case study, in which we examined the correlation between NSM and NDVI at higher resolution of $16 \mathrm{~km}$ (re-gridded from the $8 \mathrm{~km}$ dataset), and the relations between the strength of this correlation and land-cover.

\section{Results and discussion}

The strength of the correlation between summer NDVI and each drought index is shown in Fig. 1. The correlation maps show few broad areas, where positive correlations are evident in all indices. Other, mostly northern areas, show negative correlation, which is probably related to the correlation between summer temperature and precipitation, and the strong control of temperature on vegetation in these areas. Some areas show positive correlation only with part of the indices. For example, the SPI3-EMCWF and SPI3-GPCP maps show strong correlation in parts of Eastern Europe. However, for all indices, significant positive correlations were found in the rectangle areas covering Iberia $\left(9.5^{\circ} \mathrm{W}-0.5^{\circ} \mathrm{W}, 36.5^{\circ} \mathrm{N}-\right.$ $\left.43.5^{\circ} \mathrm{N}\right)$, parts of North Africa $\left(6.5^{\circ} \mathrm{W}-11.5^{\circ} \mathrm{E}, 35.5^{\circ} \mathrm{N}-\right.$ $\left.37.5^{\circ} \mathrm{N}\right)$ and Western Turkey $\left(26.5^{\circ} \mathrm{E}-31.5^{\circ} \mathrm{E}, 36.5^{\circ} \mathrm{N}-\right.$ $\left.41.5^{\circ} \mathrm{N}\right)$. In these areas, the mean correlation coefficient $(r)$ exceeded 0.4 in the two best performing indices, NSM and SC-PDSI, and the mean p-value was $<0.01$ ( $P$ is $<0.01$ for $r>0.51$ and $p<0.05$ for $r>0.37$ ). For these three areas, we have also calculated the correlation between the time-series of NDVI (averaged over each area), and drought indices (also averaged over each area). This averaging brought all datasets to the same (very coarse) resolution, and thus removed bias caused by the different original resolutions.

The correlations of the area-mean time series indicate (Table 1) that the NSM index outperformed in two areas, Iberia and Western Turkey, while SC-PDSI gave the highest correlations in one - Northern Africa. Hence, we conclude that these two indices represent the actual soil-moisture better than the PDSI, SPI3-EMCWF and SPI3-GPCP indices. Surprisingly, SPI3-GPCP performed worse than SPI3-EMCWF, 

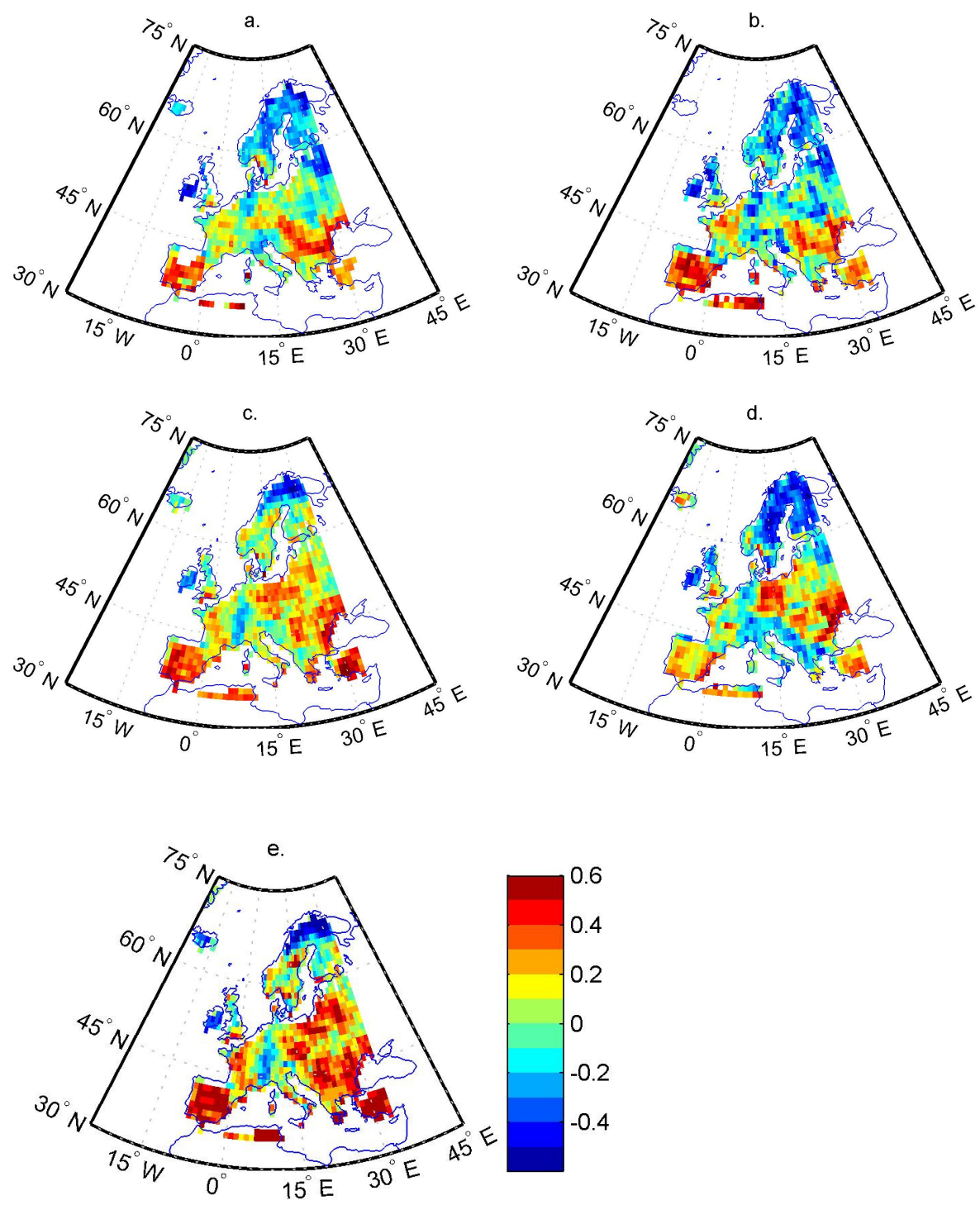

Fig. 1. Coefficients $(r)$ of correlation between interannual anomalies in Europe JJA NDVI and soil moisture indices: PDSI (a), SC-PDSI (b), SPI3-EMCWF (c), SPI3-GPCP (d) and NSM (e).

Table 1. Correlation coefficients $(r)$ between the (area-mean) interannual variability in summer (JJA) NDVI and soil-moisture estimated by various indices.

\begin{tabular}{lrrrrrr}
\hline & $\begin{array}{r}\text { SPI3- } \\
\text { GPCP }\end{array}$ & $\begin{array}{r}\text { SPI3- } \\
\text { EMCWF }\end{array}$ & PDSI & $\begin{array}{r}\text { SC- } \\
\text { PDSI }\end{array}$ & NSM & NSMS \\
\hline Iberia & 0.33 & 0.71 & 0.70 & 0.73 & 0.78 & 0.80 \\
N. Africa & 0.33 & 0.68 & 0.67 & 0.78 & 0.76 & 0.84 \\
W. Turkey & 0.31 & 0.65 & 0.45 & 0.56 & 0.78 & 0.79 \\
\hline
\end{tabular}

although the former is based on observed precipitation, and the later on modeled one. As we have expected, the correlations between soil-moisture and NDVI in spring (MAM) are not significant in Iberia and Western Turkey $(r<0.04$ for NSM), and much weaker than in summer in Northern Africa ( $r=0.25$ for NSM versus $r=0.76$ in summer). This is since soil moisture stress (and the respective drought stress) and its impact on vegetation is higher in summer when compared to spring.

The positive correlation found in Iberia, parts of North Africa and Western Turkey, is expected to relate to high sensitivity to soil-moisture. Indeed, these areas are relatively dry, and according to the TESSEL simulation the mean JJA soil-moisture is less than $83 \%$ of that of the mean value for Europe. The mean JJA temperature (EMCWF) is above $21^{\circ} \mathrm{C}$, versus less than $13.5^{\circ} \mathrm{C}$ for Europe on average. According to the Koppen-Geiger classification (Kottek et al., 2006) these areas are almost entirely under climate classified 
Table 2. The mean coefficient of correlation $(r)$ between interannual variability in summer NDVI of $16 \mathrm{~km}$ by $16 \mathrm{~km}$ grid-cells in Iberia, and NSM, stratified by fractional land cover.

\begin{tabular}{lrrrrr}
\hline$r$ & Grass Cover & $r$ & Tree Cover & $r$ & Bare Cover \\
\hline 0.15 & $0-40 \%$ & 0.35 & $0-5 \%$ & 0.22 & $0-5 \%$ \\
0.26 & $40-60 \%$ & 0.30 & $5-15 \%$ & 0.30 & $5-10 \%$ \\
0.31 & $60-70 \%$ & 0.28 & $15-30 \%$ & 0.32 & $10-20 \%$ \\
0.30 & $70-80 \%$ & 0.21 & $30-40 \%$ & 0.37 & $20-30 \%$ \\
0.30 & $80-90 \%$ & 0.18 & $40-60 \%$ & 0.44 & $30-40 \%$ \\
0.25 & $90-100 \%$ & 0.14 & $60-100 \%$ & 0.44 & $40-100 \%$ \\
\hline
\end{tabular}

as warm temperate climate (CS) with hot $(\mathrm{CSa})$ or warm (Csb) dry summers. In agreement, the NDVI in these areas is reduced in summer, while the mean for Europe shows seasonal maximum at this time (Fig. 2). We have also found no significant correlation (at $P<0.05$ ) between interannual variation in JJA temperature and NDVI at these regions, which strengthen the conclusion that soil-moisture is the leading source of variability. In addition, the plant functional type (PFT) distribution in these areas is different than those of the rest of Europe. According to the Vegetation Continuous Fields dataset (Hansen et al., 2003b), the percentage of area not cover by trees is $85 \%$ in Iberia, $95 \%$ in NorthernAfrica, and $84 \%$ in Western-Turkey, while only $78 \%$ in entire Europe. Finding theses high NDVI-drought correlations exactly where they are expected, i.e., water limited ecosystems, support our claim that the NDVI signal can be used for ranking drought indices.

We have performed a more detailed case study for Iberia, using a $16 \mathrm{~km}$ spatial resolution NDVI dataset (Table 2). The correlations coefficient in this resolution was found to be much lower than that obtained when correlating the time series of each broad geographical area (Table 1). The significant correlations in areas classified as "bare soil" indicate that at least some of these areas are sometime vegetated. The correlation with NSM was found to increase with lower tree cover. Hence, it seems that the response of grasses to soilmoisture stress is higher. Grasses, in contrast to trees, have no access to deep soil water, and as a result, we have expected that areas with low tree cover will have better correlation with the normalized soil-water of the first three model layers (down to $100 \mathrm{~cm}$ depth) that are used to derive NSM, than with NSM itself. Indeed, the correlation $(r)$ of NDVI at $16 \mathrm{~km}$ resolution with the normalized soil-water in the surface layers (which we named NSMS - Normalized Soil Moisture at the Surface) at grid-cells where the tree cover is less than $10 \%$, is 0.39 on average, versus 0.33 for the same grid-cells when we use all layers (NSM). In grid-cells where the tree-cover was high $(>50 \%)$ the correlation of NDVI with the fourth layer $(100 \mathrm{~cm}$ to $289 \mathrm{~cm})$ was not significant $(r=0.19)$ as was the correlation with $\operatorname{NSM}(r=0.13)$. It is possible that in areas with high tree-cover the Photochemi-

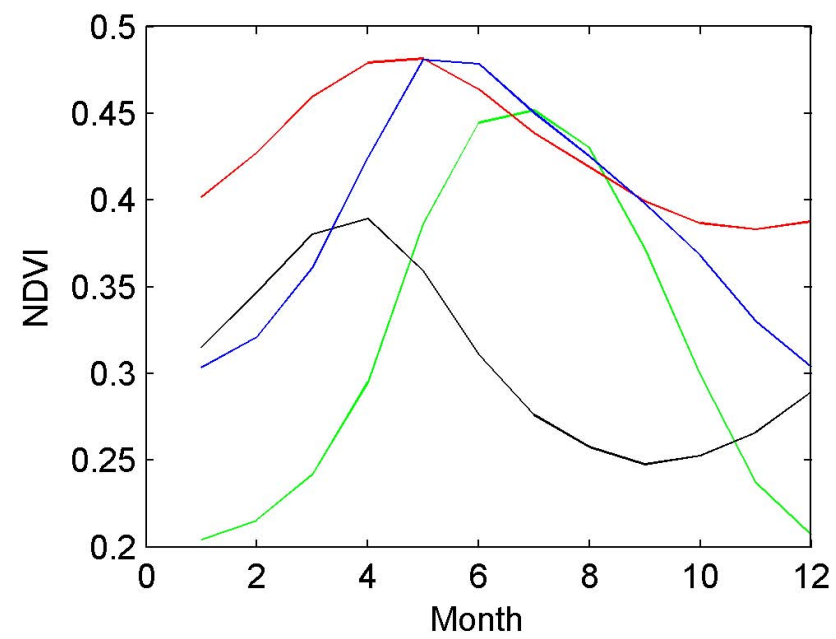

Fig. 2. Mean seasonal changes in NDVI over Europe (green), Iberia (red), Northern Africa (black) and Western Turkey (blue).

cal Reflectance Index (PRI) will be better suited for tracing drought stress than NDVI (Goerner et al., 2009). A follow-up study should also investigate if there is a different response for evergreen and deciduous trees, as well as time lags between drought-stress at monthly time resolution, and vegetation response.

Based on the above results, we have calculated also the correlation of NDVI in $1^{\circ}$ degree resolution with NSMS. The results, summarized in Table 1 , show that NSMS is better correlated with vegetation than NSM, in the three geographical areas with relatively high correlations. Moreover, NSMS had higher correlations than any other drought index; making it the most reliable one based on the criterion we have defined. The higher correlation of tree-covered surface with the fourth layer indicates that NSM also has good reliability, when the interest is estimating the soil-moisture anomalies also at deeper levels. The highly parameterized formulation of PDSI, or the simple approach of the SPI was shown to be less reliable than the more physically based water balance of the NSM, including its four layer structure. These factors seem to be major ones, and not so much the forcing data, since both the NSM and one of the SPI indices were driven by the same ERA-40 precipitation.

We have utilized the NSM to assess the relative importance of temperature and soil-moisture on NDVI in summer and spring. We divided Europe into three regions, based on summer (JJA) mean temperature ("Hot" $>19^{\circ} \mathrm{C}$, "Cold" $<16^{\circ} \mathrm{C}$, $16^{\circ} \mathrm{C}<$ "Warm" $<19^{\circ} \mathrm{C}$ ), and performed an ICA analysis on the JJA NDVI interannual anomalies in each region. The leading ICAs were then correlated with the area-mean JJA temperature, with NSM (representing soil-moisture), and with the original NDVI signal (to asses the percentage of variability captured by each IC). 
Table 3. ICA analysis results for summer (JJA) and spring (MAM) NDVI for three regions of Europe, separated by the mean summer temperature. Displayed is the percentage of NDVI variance explained by the two leading IC's, and the coefficient of determination $\left(r^{2}\right)$ between each IC and the regions anomalies of temperature and soil moisture (NSM). Empty fields indicate that no second IC was found.

\begin{tabular}{|c|c|c|c|c|c|c|}
\hline & \multicolumn{3}{|c|}{ JJA } & \multicolumn{3}{|c|}{ MAM } \\
\hline & Hot & warm & Cold & Hot & warm & Cold \\
\hline IC1-\% Expl. & 63 & 61 & 47 & 50 & 24 & 59 \\
\hline IC2-\% Expl. & 32 & 20 & 41 & 11 & & 21 \\
\hline IC1-Temp. & 0.10 & 0.09 & 0.32 & 0.52 & 0.29 & 0.34 \\
\hline IC2-Temp. & 0.00 & 0.08 & 0.31 & 0.17 & & 0.00 \\
\hline IC1-Moist & 0.36 & 0.29 & 0.06 & 0.12 & 0.05 & 0.02 \\
\hline IC2-Moist & 0.02 & 0.06 & 0.10 & 0.27 & & 0.01 \\
\hline
\end{tabular}

This process was then repeated for MAM. The results, summarized in Table 3, indicate that in summer the leading ICs for the hot and warm regions are correlated only with soil-moisture, and there is no evidence for temperature effect on NDVI. In contrast, the hot and warm regions do show dependence of NDVI on temperature in spring, and only a weak soil-moisture effect. The cold region shows only temperature effect both in summer and spring. These results indicate that in areas with mean summer temperature above $16^{\circ} \mathrm{C}$, it is possible to separate the contribution of temperature and precipitation on NDVI (and maybe also productivity) by focusing on different seasons.

\section{Conclusions}

The correlations between interannual variations in NDVI and the drought indices are highest in areas with hot and dry summers, as expected. Higher correlation is associated with grassland than with forests. The NSMS index was found to have the highest correlation with NDVI, having the best representation of the interannual variations in the surface soil-moisture stress. NSM carries additional information on deeper soil-moisture. These results have obvious implications for further soil-moisture based studies. ICA analysis of entire Europe found that in areas with summer temperature above $16^{\circ} \mathrm{C}$, the vegetation (as captured by NDVI) responses in summer, on the interannual time scale, only to variation in drought-stress and not to temperature. However, in spring the vegetation in these areas does show sensitivity to temperature. These findings have implication for change in vegetation and the carbon cycle under changing climate.
Acknowledgements. We thank Efrat Morin for fruitful discussion, and two anonymous reviewers for their comments. This research was supported by a grant from the Ring Foundation.

Edited by: W. Wagner

\section{References}

Angert, A., Biraud, S., Bonfils, C., Henning, C. C., Buermann, W., Pinzon, J., Tucker, C. J., and Fung, I.: Drier summers cancel out the $\mathrm{CO}_{2}$ uptake enhancement induced by warmer springs, $\mathrm{P}$. Natl. Acad. Sci. USA, 102, 10823-10827, 2005.

Dai, A. G., Trenberth, K. E., and Qian, T. T.: A global dataset of Palmer Drought Severity Index for 1870-2002: Relationship with soil moisture and effects of surface warming, J. Hydrometeorol., 5, 1117-1130, 2004.

Dutra, E., Viterbo, P., and Miranda, P. M. A.: ERA40 reanalysis hydrological applications in the characterization of regional drought, Geophys. Res. Lett., 35, L19402, doi:10.1029/2008GL035381, 2008.

Ferranti, L. and Viterbo, P.: The European summer of 2003: Sensitivity to soil water initial conditions, J. Climate, 19, 3659-3680, 2006.

Fung, I. Y., Doney, S. C., Lindsay, K., and John, J.: Evolution of carbon sinks in a changing climate, P. Natl. Acad. Sci. USA, 102, 11201-11206, 2005.

Goerner, A., Reichstein, M., and Rambal, S.: Tracking seasonal drought effects on ecosystem light use efficiency with satellitebased PRI in a Mediterranean forest, Remote Sens. Environ., 113, 1101-1111, 2009.

Gu, Y. X., Hunt, E., Wardlow, B., Basara, J. B., Brown, J. F., and Verdin, J. P.: Evaluation of MODIS NDVI and NDWI for vegetation drought monitoring using Oklahoma Mesonet soil moisture data, Geophys. Res. Lett., 35, L22401, doi:10.1029/2008GL035772, 2008.

Hansen, M., DeFries, R., Townshend, J. R., Carroll, M., Dimiceli, C., and Sohlberg, R.: Vegetation Continuous Fields MOD44B, 2001 Percent Tree Cover, Collection 3, University of Maryland, College Park, Maryland, 2003a

Hansen, M. C., DeFries, R. S., Townshend, J. R. G., Carroll, M., Dimiceli, C., and Sohlberg, R. A.: Development of 500 meter vegetation continuous field maps using MODIS data, IGARSS 2003: IEEE International Geoscience and Remote Sensing Symposium, Proceedings, 264-266, 2003b.

Heim, R. R.: A review of twentieth-century drought indices used in the United States, B. Am. Meteorol. Soc., 83, 1149-1165, 2002.

Hyvrinen, A. and Oja, E.: Independent component analysis: algorithms and applications, Neural Netw., 13, 411-430, doi:10.1016/S0893-6080(00)00026-5, 2000.

Ji, L. and Peters A. J.: Assessing vegetation response to drought in the northern Great Plains using vegetation and drought indices, Remote Sens. Environ., 87(1), 85-98, 2003.

Kottek, M., Grieser, J., Beck, C., Rudolf, B., and Rubel, F.: World map of the Koppen-Geiger climate classification updated, Meteorol. Z., 15, 259-263, doi:10.1127/0941-2948/2006/0130, 2006.

Lloyd-Hughes, B. and Saunders, M. A.: A drought climatology for Europe, Int. J. Climatol., 22, 1571-1592, doi:10.1002/Joc.846, 2002. 
McKee, T. B., Doesken, N. J., and Kleist, J.: The relationship of drought frequency and duration to time scales, 8th AMS Conference on Applied Meteorology, Anaheim CA., 179-184, 1993.

Palmer, W. C.: Meteorological drought, US Weather Bureau, Washington DC, 58 pp., 1965.

Pinzon, J., Brown, M. E., and Tucker, C. J.: Satellite time series correction of orbital drift artifacts using empirical mode decomposition, in: Hilbert-Huang Transform: Introduction and Applications, edited by: Huang, N., 167-186, 2005.

Seneviratne, S. I., Luthi, D., Litschi, M., and Schar, C.: Landatmosphere coupling and climate change in Europe, Nature, 443, 205-209, 2006.

Sheffield, J. and Wood, E. F.: Projected changes in drought occurrence under future global warming from multi-model, multiscenario, IPCC AR4 simulations Climate Dynamics, 31, 79-105, 2007.

Sims, A. P., Niyogi, D. D. S., and Raman, S.: Adopting drought indices for estimating soil moisture: A North Carolina case study, Geophys. Res. Lett., 29(8), 1183, doi:10.1029/2001GL013343, 2002.

Tadesse, T., Brown, J. F., and Hayes, M. J.: A new approach for predicting drought-related vegetation stress: Integrating satellite, climate, and biophysical data over the US central plains, ISPRS J. Photogramm. Remote Sens., 59, 244-253, doi:10.1016/j.isprsjprs.2005.02.003, 2005.

Tucker, C., Pinzon, J., Brown, M., Slayback, D., Pak, E., Mahoney, R., Vermote, E., and El Saleous, N.: An extended AVHRR 8km NDVI dataset compatible with MODIS and SPOT vegetation NDVI data, Int. J. Remote Sens., 26, 4485-4498, 2005.

Tucker, C. J. and Sellers, P. J.: Satellite remote-sensing of primary production, Int. J. Remote Sens., 7, 1395-1416, 1986.
Uppala, S. M., Kallberg, P. W., Simmons, A. J., Andrae, U., Bechtold, V. D., Fiorino, M., Gibson, J. K., Haseler, J., Hernandez, A., Kelly, G. A., Li, X., Onogi, K., Saarinen, S., Sokka, N., Allan, R. P., Andersson, E., Arpe, K., Balmaseda, M. A., Beljaars, A. C. M., Van De Berg, L., Bidlot, J., Bormann, N., Caires, S., Chevallier, F., Dethof, A., Dragosavac, M., Fisher, M., Fuentes, M., Hagemann, S., Holm, E., Hoskins, B. J., Isaksen, L., Janssen, P. A. E. M., Jenne, R., McNally, A. P., Mahfouf, J. F., Morcrette, J. J., Rayner, N. A., Saunders, R. W., Simon, P., Sterl, A., Trenberth, K. E., Untch, A., Vasiljevic, D., Viterbo, P., and Woollen, J.: The ERA-40 re-analysis, Q. J. Roy. Meteorol. Soc., 131, 2961-3012, doi:10.1256/Qj.04.176, 2005.

Van den Hurk, B. J. J. M., Viterbo, P., Beljaars, A. C. M., and Betts, A. K.: Offline validation of the ERA40 surface scheme, edited by: Memo, E. T., Eur. Cent. for Medium-Range Weather Forecasts, Reading, UK, 42 pp., 2000.

Van Der Schrier, G., Briffa, K. R., Jones, P. D., and Osborn, T. J.: Summer moisture variability across Europe, J. Climate, 19, 2818-2834, 2006.

Viterbo, P. and Beljaars, A. C. M.: An improved land-surface parameterization scheme in the EMCWF model and its validation, J. Climate, 8, 2716-2748, 1995.

Wang, X. W., Xie, H. J., Guan, H. D., and Zhou, X. B.: Different responses of MODIS-derived NDVI to root-zone soil moisture in semi-arid and humid regions, J. Hydrol., 340, 12-24, doi:10.1016/j.jhydrol.2007.03.022, 2007.

Wells, N., Goddard, S., and Hayes, M. J.: A self-calibrating Palmer Drought Severity Ivndex, J. Climate, 17, 2335-2351, 2004.

Xie, P. P., Janowiak, J. E., Arkin, P. A., Adler, R., Gruber, A., Ferraro, R., Huffman, G. J., and Curtis, S.: GPCP Pentad precipitation analyses: An experimental dataset based on gauge observations and satellite estimates, J. Climate, 16, 2197-2214, 2003. 